\title{
Self-regulation as a way to prevent professional burnout of teachers of higher education institutions
}

\author{
I.F. Timerbulatov ${ }^{1 *}$, I.R. Khabibullina ${ }^{2}$, and G.F. Tulitbaeva ${ }^{3}$ \\ ${ }^{1}$ Bashkir State Medical University, Ufa, Russia \\ 2 Bashkir State University, Ufa, Russia \\ ${ }^{3}$ Bashkir State University, Ufa, Russia
}

\begin{abstract}
This article is devoted to the study of the issues of identifying the optimal working conditions of a teacher of a higher educational institution and the significant characteristics of the style of his activity (in particular, the peculiarities of the style of self-regulation) allows us to identify the factors that prevent the development of professional burnout. The significance of the work also lies in the possibility of using the results of the study both in the process of preventing professional burnout of teachers, and in conducting scientific research on such topics. The research materials can become the basis for educational work. In this regard, an experimental study is becoming relevant, the purpose of which is to study the influence of professional burnout on the individual style of pedagogical activity of a higher school teacher.
\end{abstract}

\section{A problem statement}

Teacher burnout is a particular type of stress at work, a state of physical, emotional, or mental exhaustion combined with doubts about the competence and value of the job.

The problem of professional burnout is one of the most relevant, since it has a negative impact on many indicators of the organization's activities. The negative consequences of professional burnout should not be underestimated, and the measures implemented in this area in some cases are of a formal nature.

The interest in the problems of style in psychology has been stable and constant for many decades. We study the lifestyle and personality style, the style of cognitive processes $[1,2]$.

The problem of individual style of self-regulation of pedagogical activity is discussed quite widely. Styles of implementation of certain aspects of pedagogical activity (communication, assessment, educational influence, etc.) are studied; various groups of operations of the style of pedagogical activity are distinguished; levels, stages of formation, structure of style are established; the character of determination of style manifestations by individual properties of teachers is investigated; attempts are made to consider the

\footnotetext{
*Corresponding author: prof-ped.gpa@mail.ru
} 
individual style of pedagogical activity as an integral system of various pedagogical actions. In studies of pedagogical activity, the problem of the relationship between individual style and professional burnout is discussed less widely.

In this regard, an experimental study is becoming relevant, the purpose of which is to study the influence of professional burnout on the individual style of pedagogical activity of a higher school teacher.

The symptoms of professional burnout indicate the characteristic features of prolonged stress and mental overload, which lead or may lead to complete disintegration of various mental spheres, and above all - emotional. The development of the syndrome is of a stadium nature. At first, there are significant energy costs-a consequence of an extremely high positive attitude to the performance of professional activities. As the syndrome develops, a feeling of fatigue appears, which is gradually replaced by frustration, a decrease in interest in their work $[3,4]$.

The adaptive purpose of "burnout" is the ability to reduce the consumption of energy resources and thereby protect the body from the threat of exhaustion. However, like many adaptive reactions, this protective mechanism has only relative expediency and its negative consequences are manifested in a decrease in the success of professional activities and deterioration of relationships with partners, and in some cases may be accompanied by the appearance of various kinds of psychosomatic disorders. Thus, the achieved state of "security", in fact, leads to professional maladaptation and disruption of contacts with other people. Therefore, we can consider a well-founded approach to the problem of "emotional burnout" as a special type of occupational disease («communication disease»).

\subsection{The objective of the work}

The concept of "emotional burnout" appeared in psychology relatively recently. Recently, it is widely used in scientific texts and the lexicon of psychiatrists, medical and social psychologists, sounds from TV screens and flashes on the pages of popular publications. Representatives of many professions whose activities are related to communication are subject to symptoms of gradual emotional fatigue and emptiness.

"Emotional burnout is a psychological defense mechanism developed by a person in the form of complete or partial exclusion of emotions (lowering their energy) in response to selected psychotraumatic influences". Emotional burnout is an acquired stereotype of emotional, most often professional behavior. At the same time, its dysfunctional consequences may arise, when "burnout" negatively affects the performance of professional activities and relationships with partners.

The problem of human stress resistance in various professions has long attracted the attention of psychologists of various fields. In the classical studies of Selye, and later Lazarus, Rosepman and Friedman, it was shown that prolonged exposure to stress leads to such adverse consequences as a decrease in the overall mental stability of the body, the appearance of a sense of dissatisfaction with the results of their activities, a tendency to refuse to perform tasks in situations of increased demands, failures and defeats. An analysis of the factors that cause such symptoms in various activities has shown that there are a number of professions in which a person begins to experience a sense of internal emotional emptiness due to the need for constant contact with other people. The term "powerless helper" has appeared to describe the state of mental overload in social professions $[5,6]$.

The professional activity of a person largely depends on his individual characteristics. Individualization, which can be considered as a specific form of development, is also a way of adapting a person to the structure of labor activity objectively set from the outside. The process of individualization in the work of a teacher can have different expressions:

- individual differences; 
- individual style;

-individuality $[5,7]$.

Individual differences in pedagogical work - individual episodic manifestations of the peculiarities of the performance of a given person's professional activity, professional communication.

Individual differences can manifest themselves in almost all aspects of work: in the choice of profession and the subject of work, in the choice of specialization, tasks and the situation within the profession, in the attitude to the profession and professional motivation, in the choice of ways of working, etc. The formation of individual differences occurs in the course of inclusion, integration of a person into the system of social relations, comparison of oneself with other people. Becoming stable as a result of the process of professionalization, individual differences can contribute to the formation of an individual style of activity.

In pedagogical activity, characterized by the fact that it is carried out in subject-subject interaction in specific educational situations of the organization and management of students ' educational activities, these features are also correlated with the nature of interaction, with the nature of the organization of activities, the subject-professional competence of the teacher and the nature of communication.

The individuality of a teacher is an expression of the uniqueness, originality of a person's personality in work and his professional worldview. Becoming an individual means self-determination of the ability for individual self-development, self-giving of one's abilities for the benefit of other people. The individuality, integrity of the professional personality is most clearly manifested when it is combined with a high spirituality, humanistic orientation. The individual style of the teacher is the main factor in the formation of his authority among students $[3,8]$.

\section{Results of the research}

The study was conducted in the period from September 2018 to September 2020 on the basis of the Bashkir State University. The total sample of the study was 54 people: 37 women and 17 men aged 27 to 66 years.

The psychodiagnostic tools include the following psychodiagnostic techniques:

1. Burnout questionnaire by V.V. Boyko,

2. Questionnaire "Style of self-regulation of behavior" (SSPM) in the modification of V.I. Morosanova.

The results obtained when testing teachers using the method of diagnosing emotional burnout of the personality of V.V. Boyko are summarized in Table 1.

All subjects are divided by the number of points scored, both in individual phases, and by the total number of points scored.

The entire sample can be divided into three groups, according to such criteria as the formation of phases:

group 1 - the syndrome is fully formed in at least one of the phases (i.e. the total number of points in one of the phases is greater than or equal to 61);

group 2 - the syndrome is in the stage of formation in at least one of the phases (i.e. the total number of points in one of the phases is in the range from 37 to 60 points);

Group 3 - the syndrome has not formed (i.e. the total number of points in any of the phases does not exceed 36 points) (Figure 1). 


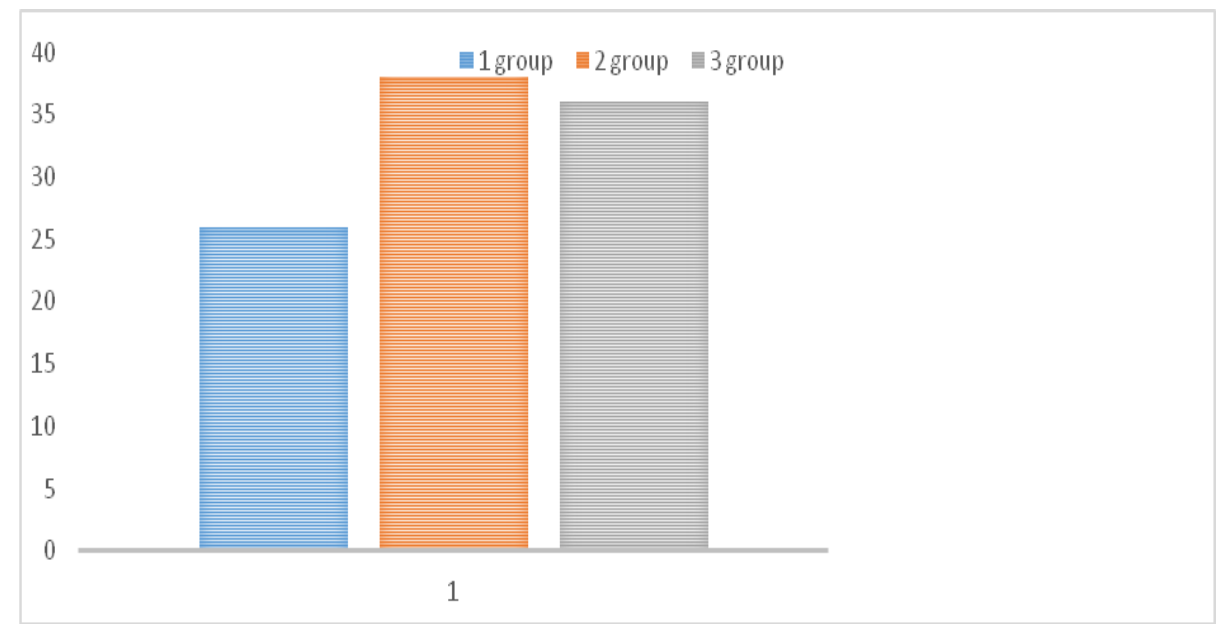

Fig. 1. Distribution of teachers by stages of emotional burnout, $\%$.

Figure 1 shows that the first group included 13 teachers, which is $26 \%$; the second group - 19 people, which is $38 \%$; the third group- 18 people, which is $36 \%$.

Thus, we can conclude that the most numerous group of teachers was a group of teachers with burnout syndrome, formed at least in one of the phases. Individuals who fall into this group are characterized by a drop in overall energy tone and a weakening of the nervous system. "Burnout" becomes an integral attribute of these teachers. And the smallest group is the group with an unformed syndrome. These teachers "started" the mechanism in the formation of emotional burnout. Teachers experience personal anxiety, disappointment in themselves, in the profession or place of work (Figure 2).

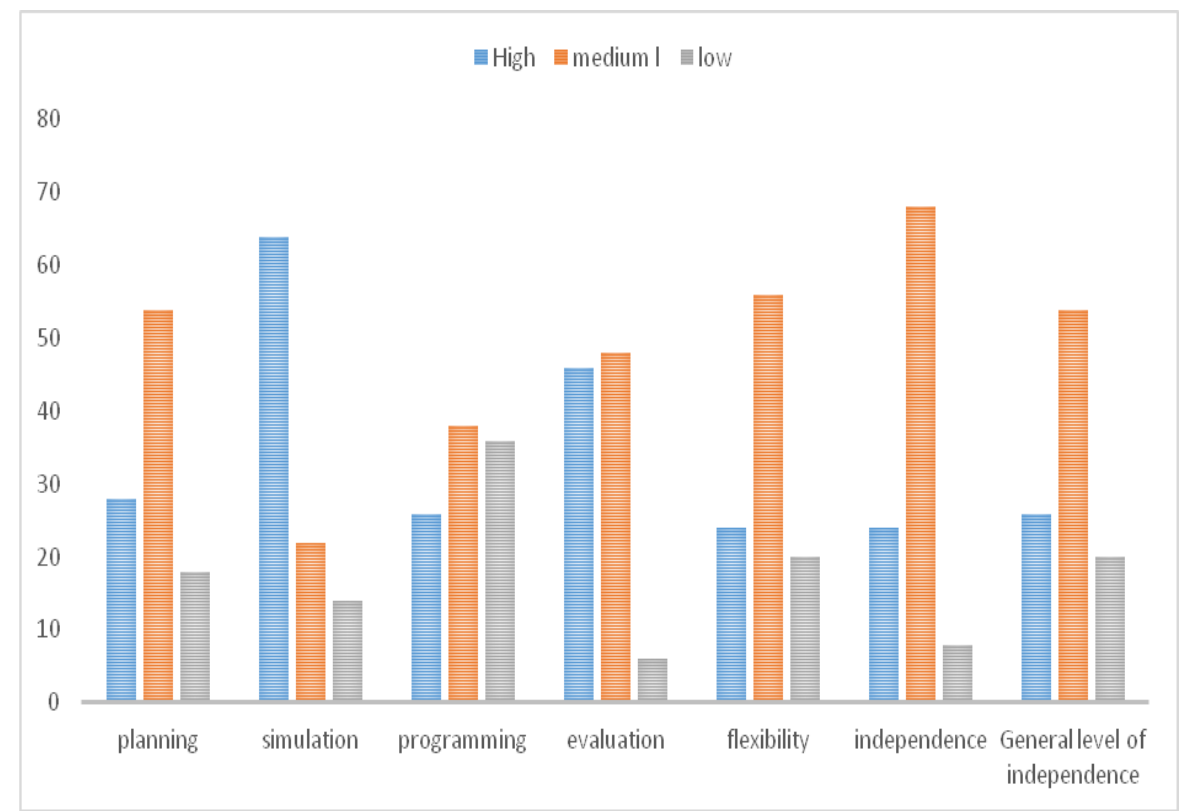

Fig. 2. The results of the diagnostics style of self-regulation in teachers, $\%$.

Note: 1 - the scale of "planning," scale 2 "modeling" 3 - bar "programming", 4 - scale "assessment results", 5 - scale flexibility, 6 - scale "self-sufficiency" 7 - scale "General level of self-regulation" 
So, according to the results of the analysis of the self-regulation styles methodology, it was found that the subjects most often use such self-regulation styles as "evaluation of results" and "independence".

Thus, the subjects are more dominated by the average level (73\%) of burnout and a high level $(64 \%)$ of volitional self-regulation. The most preferred styles of self-regulation are "evaluation of results" (71\%) and "independence" (61\%).

At the next stage of our study, we subjected the results to a correlation analysis using the r-Pearson correlation coefficient between self-regulation indicators and the level of burnout syndrome. The results are presented in table 1 .

The analysis revealed a statistically significant inversely proportional correlation between the self-regulation indicator "planning" and the level of emotional burnout $(r=-$ 0.360 , with $\mathrm{p}<0.05$ ). This fact indicates that the higher the conscious planning of professional activity is developed, the less the level of emotional burnout will be developed (Table 1).

Table 1. Relationship of self-regulation with burnout syndrome.

\begin{tabular}{|l|c|}
\hline \multicolumn{1}{|c|}{ Self-regulation style } & Correlation coefficient, $\boldsymbol{r}=$ \\
\hline planning & -0.360 \\
\hline modeling & -0.505 \\
\hline programming & -0.356 \\
\hline evaluation of results & -0.456 \\
\hline general level of self-regulation & -0.361 \\
\hline
\end{tabular}

The empirical value of the correlation coefficient greater than its critical value $(\mathrm{r}=$ 0.505 , at $\mathrm{p} \leq 0.01$ ) indicates the presence of a statistically significant inversely proportional relationship between the variables "modeling" and the level of emotional burnout. Consequently, the more developed the individual's ideas about the internal and external conditions of activity, as well as the measure of their awareness, adequacy and accuracy, the lower the level of emotional burnout will be.

An inversely proportional correlation was established between the self-regulation indicator "programming" and the level of teachers ' emotional burnout $(\mathrm{r}=-0.356$, with $\mathrm{p}<0.05$ ). This circumstance indicates the following: the higher a person's level of conscious programming of actions is developed, the lower the level of emotional burnout will be.

There is an inversely proportional relationship between the variables "evaluation of results" and the level of burnout $(\mathrm{r}=-0.456$, at $\mathrm{p} \leq 0.01)$. This circumstance indicates the following: the higher the level of development and adequacy of self-assessment and their behavior and activities, the lower the level of emotional burnout will be developed.

The r-Pearson correlation coefficient between the indicators of the general level of selfregulation and the level of emotional burnout, equal to $-0.361 \quad(p \leq 0.05)$, indicates the presence of a statistically significant inversely proportional relationship between these variables, which means the following: the higher the overall level of development of conscious self-regulation, the lower the level of emotional burnout.

Thus, according to the results of the correlation analysis, the relationship between professional burnout and self-regulation was found in the teachers of the BSPU named after M. Akmulla.

\section{Conclusions}

The identification of the optimal working conditions of a teacher of a higher educational institution and the significant characteristics of the style of his activity (in particular, the peculiarities of the style of self-regulation) allows us to identify the factors that prevent the development of professional burnout. The significance of the work also lies in the 
possibility of using the results of the study both in the process of preventing professional burnout of teachers, and in conducting scientific research on such topics. Research aimed at identifying and preventing professional burnout of a higher school teacher, improving the subjective well-being and satisfaction with their work and the quality of life of the teaching staff of a higher educational institution can be used in their life activities, in the process of consulting work of their immediate environment, as well as in conducting trainings and seminars aimed at providing psychological assistance to teachers. The research materials can become the basis for educational work.

The problem of individual style of self-regulation of pedagogical activity is discussed quite widely. Styles of implementation of certain aspects of pedagogical activity (communication, assessment, educational influence, etc.) are studied; various groups of operations of the style of pedagogical activity are distinguished; levels, stages of formation, structure of style are established; the character of determination of style manifestations by individual properties of teachers is investigated; attempts are made to consider the individual style of pedagogical activity as an integral system of various pedagogical actions. In studies of pedagogical activity, the problem of the relationship between individual style and professional burnout is discussed less widely.

In this regard, an experimental study is becoming relevant, the purpose of which is to study the influence of professional burnout on the individual style of pedagogical activity of a higher school teacher.

In the course of this study, the following hypotheses were put forward: 1) various organizational working conditions (the order and content of activities, work requirements, work resources) and individual-style features of self-regulation of university teachers ' activities can act as factors for the development of professional burnout syndrome. 2) Teachers with a high level of burnout are characterized by a low level of self-regulation. 3) Professional burnout negatively affects the individual style of activity of the teacher.

The following conclusions were made:

The individual style of the teacher's activity is an integral dynamic characteristic of the individual, which is a relatively stable, open, self-regulating system of interrelated, individually unique actions and reflects the specifics of the teacher's interaction with students in the course of professional activity. The individual style of activity serves as a way to realize the creative potential of the teacher and significantly affects the effectiveness of his professional work, the formation of a professional Self.

The structure of the individual style of activity of teachers is a set of structural and functional components in all the variety of relations and connections that exist between them.

The optimal style of activity ensures effective interaction between the teacher and students with the most rational use of individual opportunities and resources in the specific conditions of pedagogical activity, i.e. the optimal individual style of activity provides the greatest result with minimal time and effort. It is highly consistent with the capabilities of the teacher, considered as an individual, a person and a subject of activity.

The dominant symptoms are the following:

"experience of psychotraumatic circumstances" (52.5\%), this means that teachers experience the impact of psychotraumatic factors, increasing tension, which results in despair and indignation, the insolubility of the situation leads to the development of burnout;

"the expansion of the sphere of saving emotions" (47.5\%) suggests that this form of protection is carried out outside the professional sphere, i.e. in communication with relatives and friends. At work, these people are kept in accordance with the regulations, and at home they are closed or, even worse, ready to send everyone away; 
"inadequate emotional response" (32.5\%) indicates that the teacher ceases to catch the difference between the economical display of emotions and inadequate emotional response. Inadequate" economy " of emotions limits the emotional return due to selective response during work contacts. At the same time, it seems to the person that he is acting in an acceptable way, and the student at the same time feels quite different - emotional callousness, indifference, disrespect.

We also see that most of the subjects with the formed syndrome are in the phase of "resistance" - resistance $35 \%$ of them have resistance to increasing stress, teachers consciously or not, strive for psychological comfort, to reduce the pressure of external circumstances.

In a comparative analysis of groups with established burnout and with uncomplicated ones, the following conclusions can be drawn:

- teachers with uncomplicated burnout have higher indicators of the components of the individual style of activity than teachers with established burnout.

Statistically significant differences were noted for the following components:

1) preparatory (I);

2) organizational (II);

3) communicative (III);

4) Stimulating (VI);

5) Disciplinarian (V);

6) control (VIII).

Teachers, with the established burnout, it is difficult to carry out meaningful preparation for classes, as they have scattered attention, they are overcome by a feeling of fatigue. In these subjects, the need for planning is less pronounced. Self-regulatory training can also not be effective due to the lack of a positive attitude to work.

Teachers with burnout experience difficulties in solving organizational and communication tasks, as they do not always respond adequately to the situation, and work contacts become selective. There are complaints about "insufficient recognition of the merits and value of the teacher's work". They tend to perceive organizational shortcomings as "incompetence and / or rigidity of supervisors and supervisors".

A group of teachers with a high level of professional burnout is characterized by the following features: less developed need for planning, more frequent changes in work goals, lower level of achievement of goals, less realistic planning, less adequate assessment of internal conditions and external circumstances of work, less stable attitude to the consequences of their actions, frequent difficulties in identifying goals and building a program of actions that are adequate to the current situation, inability to identify significant changes in the situation, less developed ability to make a program (algorithm) of their own actions, a tendency to act through trial and error, more impulsive actions, less developed systematic vision of the situation, less critical of their own actions, less developed ability to notice their mistakes and respond quickly to them, inability to formulate criteria for achieving goals and track their implementation, a tendency to deteriorate the quality and effectiveness of professional activities with an increase in the amount of work, the deterioration of the psychophysiological state or the occurrence of external difficulties, with fewer resources to compensate for the unfavorable personal characteristics for professional activity.

Individual and personal characteristics that allow you to prevent the development of professional burnout syndrome of a higher school teacher are: high self-control, emotional and stress resistance, self-reflection, self-confidence, the need for personal and spiritual and professional growth, the ability to freely express their feelings, awareness of their unity with the world around them and a value attitude to themselves, to other people, to professional activities. 


\section{References}

1. N.A. Aristova, The Syndrome of emotional burnout of teachers of high schools, The book psychology and pedagogy in the system of modern education, 7-10 (2017)

2. G.N. Izmailov, Comparative analysis of emotional burnout of teachers, and the teachers of the school, in the collection: problems and prospects of international transfer of innovative technologies, 37-41 (2017)

3. G.N. Izmailova, Features of emotional burnout of teachers with different experience, In the collection: Self-development in pedagogy and psychology, 96-100 (2017)

4. A.A. Kolesnichenko, Yu.O. Petrova and A.V. Polkovnikova, The teacher's emotional "burnout" syndrome and its prevention, in the collection: digital society in the context of personal development, 138-141 (2018)

5. Y. Gus'kov and O.N. Inkin, Prevention of emotional burnout of the teacher as a means of improving his professional reliability, In the collection: the modernization of agricultural education: integrating science and practice, 7-10 (2017)

6. A.V. Nelyapina, Emotional burnout among teachers of general educational institutions, Forum of Young Scientists, 3(7), 329-331 (2017)

7. M.A. Petrenko at all, Problem of emotional burnout of the teacher, The Scientific view of the future, 3(1), 71-79 (2016)

8. H.A. Sharabarin, and G.N. Boronina, Emotional burnout of teachers: the causes and results of the research, The New science: From the idea to the result, 11-4, 136-139 (2016)

9. M.V. Kuznetsova, and I.E. Prikhodko, Prevention of the syndrome of emotional burnout in the activities of teachers, Education. Career. Society, 2(45), 38-41 (2015)

10. A.S. Leonov, Emotional burnout of teachers of secondary and higher education: a comparative analysis, Collection of scientific works, 31-35 (2017)

11. M.V. Smagina, and Yu.S. Kuzubova, Problems of emotional burnout of teachers Development of modern education: theory, methodology and practice, 1(11), 62-65 (2017) 